\title{
Residual stresses in porcelain tiles. Measurement and process variables assessment
}

\author{
E. Sánchez ${ }^{(\mathrm{a})}$, V. Sanz ${ }^{(\mathrm{a})}$, J. Castellano ${ }^{\left(\mathrm{a},{ }^{*}\right)}$, J. Sales ${ }^{(\mathrm{b})}$, K. Kayac1 ${ }^{(\mathrm{c})}$, M.U. Taşkıran ${ }^{(\mathrm{c})}$, \\ Ü.E. Anıl ${ }^{(\mathrm{c})}$, Ş. Türk ${ }^{(\mathrm{c})}$ \\ (a) Instituto de Tecnología Cerámica (ITC), Universitat Jaume I, 12071, Castellón, Spain \\ (b) GEA CERAMICA S.L., Castellón, Spain \\ (c) Kaleseramik Canakkale Kalebodur, Çan, Turkey
}

Enrique Sánchez

Email: enrique.sanchez@itc.uji.es

Vicente Sanz

Email: vicente.sanz@itc.uji.es

Javier Castellano*

Email: javier.castellano@itc.uji.es

Telephone number: $(+34) 964342424$

Fax number: (+34) 964342425

Juan Sales

Email: juansalesgil@gmail.com

Kağan Kayaci

Email: kagankayaci@kale.com.tr

Ugur Taskiran

Email: ugurtaskiran@kale.com.tr

Ümit Anil

Email: umitenginanil@kale.com.tr

Şenay Türk

Email: senaykaya@kale.com.tr 


\begin{abstract}
This research addresses the residual stresses phenomenon taking place during the manufacture of porcelain tiles. Residual stresses were quantified by the strain relaxation slotting method. The method is based on the fact that stresses are released when a slot is made leading to a curvature change.

Once the method was validated, the impact of process variables such as starting body composition, temperature and cooling rate of firing cycle was investigated. Findings showed that cooling rate was the most influencing variable whereas Young's modulus of fired specimens also play a significant role. Symmetry of the parabolic residual stress profile denoted homogenous cooling on upper and lower tile surfaces during the cooling step. In addition, it was observed that polishing of a stressed tile gives rise to a decreasing of deformation as a consequence of stress release by mechanical grinding.
\end{abstract}

Keywords: Residual stresses, strain relaxation method, porcelain tiles, process variables, polishing.

\title{
1 Introduction
}

Residual stresses develop inside a material due to sudden changes in temperature, viscous deformations or other causes and remain once the applied external force ceases. Residual stresses in ceramic tile manufacturing generated during the cooling stage of the industrial firing cycle are mainly of two types: i) stresses of thermal origin caused by thermal gradients within the piece as a result of high cooling rate and ii) stresses caused by mismatch between the thermal expansion of body and glaze [1].

To better understand the origin of thermal residual stresses, it is worthwhile analyzing an industrial firing cycle scheme for ceramic tiles fired in a typical roller kiln, such as the one detailed in Figure 1. These cycles, although very dependent on the nature and characteristics (size) of the product to be manufactured, are generally very fast, ranging from 50 to 70 minutes. As can be seen in this figure, the cooling stage can be divided, in turn, into three stretches: i) a rapid cooling from the maximum firing temperature to approximately $650^{\circ} \mathrm{C}$, ii) indirect slow cooling between $650{ }^{\circ} \mathrm{C}$ and $500{ }^{\circ} \mathrm{C}$, in this stretch the cooling rate is drastically reduced to dampen the stresses produced by the quartz 
allotropic change that takes place at $573{ }^{\circ} \mathrm{C}$ and iii) a final rapid cooling to room temperature.

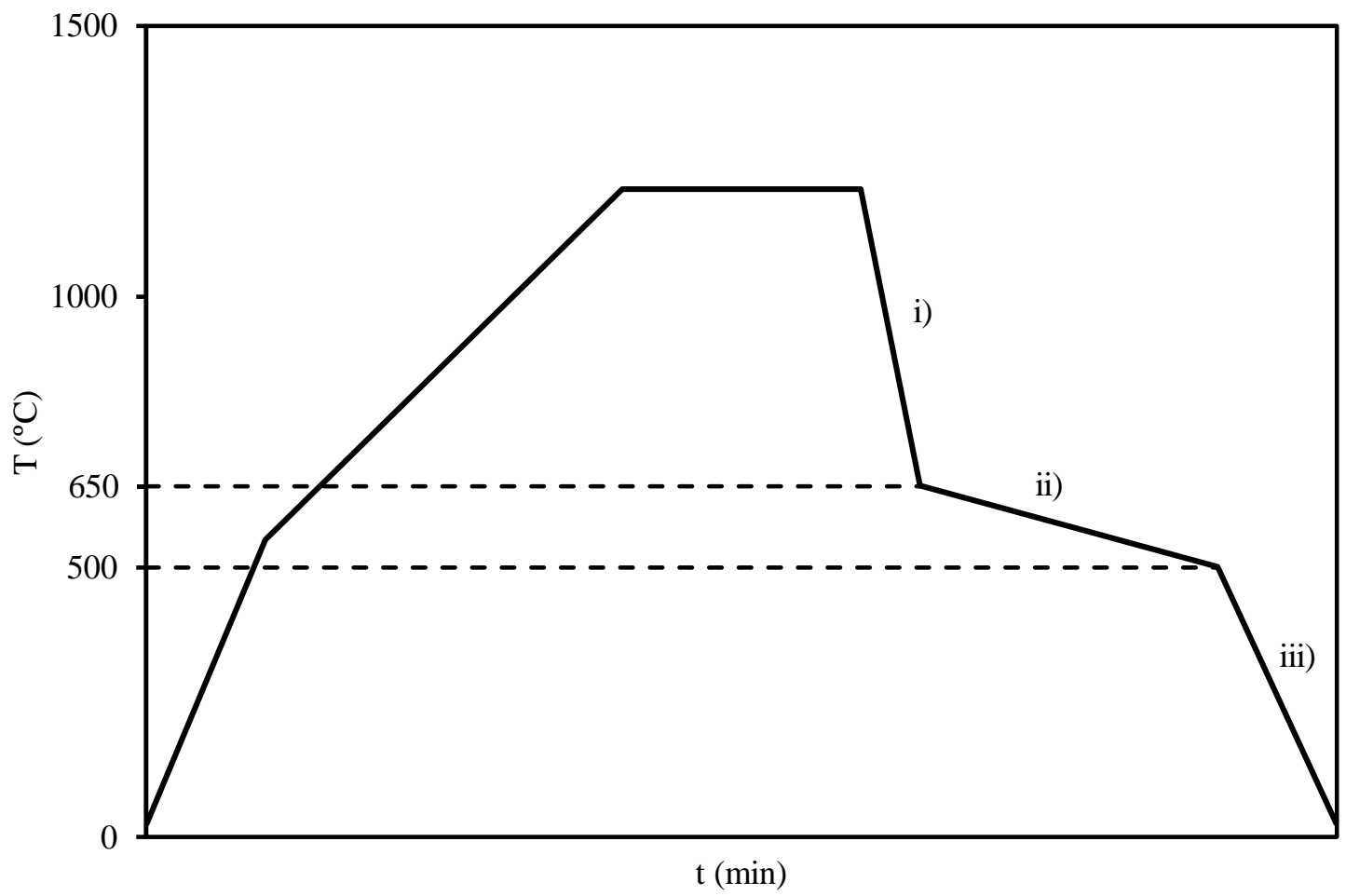

Figure 1. General scheme of a fast firing cycle in roller kilns for ceramic tiles including the three cooling stretches as set out in the text

During the first rapid cooling stretch, the high cooling rate (higher than $100{ }^{\circ} \mathrm{C} /$ minute) and the low thermal conductivity of the ceramic material lead to significant temperature differences between the surface and the center of the piece, and therefore to the development of residual stresses in the material. To understand this phenomenon, it is interesting to resemble the tempering that is regularly used in the glass industry to increase the mechanical strength of glass [2]. During tempering, the glass undergoes rapid cooling; its surface immediately becomes rigid, contracting, while its interior is maintained at high temperature in the fluid state given the low thermal conductivity of the material. As the piece continues to cool, its interior tends to contract but this shrinkage is impeded because its external surfaces are already rigid. As a result, strong compressive stresses develop on the surface, counteracted by internal tensile stresses. Upon reaching the ambient temperature, the material will present a parabolic stress profile along its thickness. 
Similarly, as indicated by De Noni et al, ceramic tiles usually present compressive stresses on their surface as a consequence of rapid industrial cooling [3]. The stress profile and the maximum compression and traction values mainly depend on temperature gradient, cooling rate and thermal properties of the material.

With regard to residual stresses caused by body and glaze expansion mismatch, these will only manifest in the case of glazed tiles, in which case they may become predominant. Its magnitude depends on several factors: difference of thermal expansion between the body and glaze, modulus of elasticity of both materials, glaze/body relative thickness and the effective glaze fit temperature [4]. However, in unglazed or poorly decorated tiles, the contribution of this stress is negligible.

Nowadays, porcelain stoneware tile has become in the most demanded product for use in flooring surfaces. The spectacular growth that the manufacture of porcelain stoneware tile has undergone in the last years deals with its good technical and functional performance associated to the impervious feature of the sintered product, together with the great technological advance that the ceramic tile manufacturing sector is experiencing [5]. Consequently, porcelain stoneware tiles account for more than $30 \%$ of the total worldwide floor tile production. In parallel to this huge production growth, larger and larger sizes which can reach higher than one meter length produced at progressively faster firing cycles are being increasingly demanded by the market. Larger sizes dramatically increase the risk for curvatures and residual stresses to appear during fast firing cycles. In addition, a significant amount of porcelain tile production consists in unglazed or slightly decorated tiles, therefore porcelain stoneware tiles represent a good model tile to assess residual stresses provoked by thermal gradient inside an industrial kiln. Sometimes, a polishing process can follow the firing step; this mechanical operation can also impact on the final residual stress resulting in unexpected tile deformations.

The study of residual stresses has been a fundamental research field in the design of structures and materials of very diverse nature such as concrete [6], metals [7], glass [8] composites [9] and advanced ceramics [10], [11]. However, its application to the case of traditional ceramic products in general, and the manufacture of ceramic tiles in particular, has been very scarce so far [1], [12]. As mentioned above, the manufacturing requirements (fast firing cycles) and product demands (large formats) have led to the need 
to address, in a rigorous way, the problem of residual stresses of thermal origin during the manufacture of porcelain tiles.

In the works previously discussed on residual stresses in ceramic tiles, Cantavella et al [12] determined thermal stresses inside unglazed porcelain tiles by using the strain relaxation method, also known as the crack-compliance technique [13][14]. These authors showed that for two different commercial products, tiles presented similar stresses profile with compressive stresses at the tile surface. The stress profiles were slightly asymmetric with higher stresses next to the upper surface. However, apart from this research, the effect of influencing variables, such as cooling rate, firing temperature or body composition on residual stresses has not been addressed yet. Besides, the influence that the polishing stage of porcelain tile can exert on residual stress and deformation of fired tiles has not been either considered in any previous research.

As a consequence of the above, the following research is proposed, which aims to determine the effect of a priori, most influential process variables on residual thermal stresses in unglazed porcelain tiles. The strain relaxation method was used to determine the residual stresses. The effect of cooling rate and maximum temperature of the firing cycle, as well as the starting composition on residual stresses were evaluated. Finally, the influence that the polishing stage exerts on residual stresses present in fired pieces was also assessed.

\section{Experimental procedure}

\subsection{Materials}

Two industrial, standard porcelain tile spray-dry powders were used (STD-T from Turkey and STD-S from Spain). Table 1 shows the mineralogical and chemical composition of this powder determined by X-ray diffraction (XRD) and X-ray fluorescence (XRF), respectively. The powders are basically made up of kaolinitic (plastic) clay, sodium feldspar and feldsphatic sand while STD-S sample contains a higher amount of silica than STD-T powder. For comparative purposes, a highly fluxing redware floor tile spray-dry powder employed in the Spanish tile industry was also used (referenced RW powder). Its chemical and mineralogical composition are also included in Table 1. Together with these two industrial powders, other two alkaline-earth fluxing additives also typically employed in porcelain tile manufacturing were used: dolomite and magnesite. Chemical analysis of 
dolomite and magnesite samples are omitted since they were almost pure substances. These two raw materials were previously dry-ground in a ball mill to obtain a maximum particle size down to $40 \mu \mathrm{m}$.

Table 1. Chemical and mineralogical composition of the two types of industrial spraydry powders used: porcelain tile (STD-T and STD-S) and redware floor tile (RW). Chemical composition in wt \%

\begin{tabular}{|c|c|c|c|}
\hline Compound & STD-T & STD-S & RW \\
\hline $\mathrm{SiO}_{2}$ & 65.70 & 73.00 & 61.90 \\
\hline $\mathrm{Al}_{2} \mathrm{O}_{3}$ & 22.13 & 17.07 & 18.10 \\
\hline $\mathrm{Fe}_{2} \mathrm{O}_{3}$ & 0.21 & 0.46 & 6.50 \\
\hline $\mathrm{Na}_{2} \mathrm{O}$ & 5.15 & 3.62 & 0.53 \\
\hline $\mathrm{K}_{2} \mathrm{O}$ & 0.62 & 1.61 & 3.14 \\
\hline $\mathrm{CaO}$ & 0.35 & 0.43 & 0.98 \\
\hline $\mathrm{MgO}$ & 0.68 & 0.29 & 1.48 \\
\hline $\mathrm{TiO}_{2}$ & 0.40 & 0.72 & 0.92 \\
\hline L.O.I & 4.76 & 2.79 & 6.42 \\
\hline \multirow{5}{*}{ 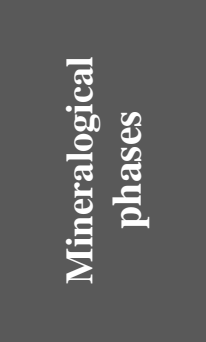 } & Kaolinite & Kaolinite & Kaolinite \\
\hline & Quartz & Quartz & Quartz \\
\hline & Illite & Illite & Illite \\
\hline & \multirow{2}{*}{ Others } & \multirow{2}{*}{ Others } & Hematite \\
\hline & & & Others \\
\hline
\end{tabular}

From the STD-S porcelain tile spray-dry powder, two other compositions were formulated by adding fixed amounts of the fluxing aids, i.e., dolomite and magnesite: 2.1 wt $\%$ of dolomite and 0.7 wt $\%$ of magnesite, respectively. These fixed amounts were optimised from previous research [15]. The new compositions were named D (dolomite addition) and $\mathrm{M}$ (magnesite addition). The spray-dry powder and each fluxing additive were mixed in a ball mill with water in a weight ratio solids/water 1:1 for 30 minutes, then the resulting suspension dried in a laboratory spray-drier (Büchi B-191) to obtain the dry powder. 


\subsection{Methods}

To assess pressing and firing behaviour, cylindrical test pieces about $5 \mathrm{~mm}$ thick and 50 $\mathrm{mm}$ in diameter were formed from industrial (STDs and RW) and laboratory (D and M) powders. In addition, parallelepiped test pieces measuring $80 \times 20 \mathrm{~mm}$, were prepared to determine the residual stresses. Regardless the geometry of the pieces, the bodies were formed at a moisture content of $6 \%$ (on a dry basis) by uniaxial pressing at a constant pressure of $400 \mathrm{~kg} / \mathrm{cm}^{2}$. For the RW powder, pressing pressure was lower $\left(250 \mathrm{~kg} / \mathrm{cm}^{2}\right)$ following the industrial practice. After they had been pressed, the test pieces were sintered in an electric laboratory kiln with the following common firing cycle: a heating ramp of $70{ }^{\circ} \mathrm{C} / \mathrm{min}$ between $25^{\circ} \mathrm{C}$ and $500{ }^{\circ} \mathrm{C}$ and $25^{\circ} \mathrm{C} / \mathrm{min}$ from $500{ }^{\circ} \mathrm{C}$ to the respective peak firing temperature. The residence time at peak firing temperature was 6 minutes. The peak firing temperatures encompassed the range $1170-1240{ }^{\circ} \mathrm{C}$, depending on each experiment. For cooling rate assessment, two very different cooling modes were tested: C1 and C2. C1 cooling corresponds to laboratory kiln cooling following the standard ventilation system. On the contrary, $\mathrm{C} 2$ cooling took place outside the kiln using a rapid, quenching system similar to that previously reported by De Noni et al [16]. Basically, the system consisted in direct application of compressed air to both upper and lower surfaces of tile samples removed from the kiln just after the soaking time at the maximum firing temperature and then placed on a perforated refractory grid. The average cooling rates reached by these two cooling modes were as follows: 0.7 and $9.0{ }^{\circ} \mathrm{C} / \mathrm{s}$ for $\mathrm{C} 1$ and $\mathrm{C} 2$ modes respectively. It should be noted that the industrial cooling rate is closer to that of cycle $\mathrm{C} 2$ rather than $\mathrm{C} 1$.

The measurements of the dry and fired dimensions of test pieces were made using a slide calliper. Unfired bulk density was measured by means of the mercury displacement method. The technological properties of fired test pieces were evaluated by performing the following tests: linear shrinkage, bulk density and water absorption. Fired bulk density was also measured using the mercury displacement method; firing shrinkage was assessed as the difference between dry and fired diameters, defining these parameters on a dry basis. Water absorption was performed by the impregnation method under vacuum. In this method, the water uptake is calculated by measuring the gain in test piece weight, after being subjected to a vacuum pressure of $91 \mathrm{kPa}$ for 30 minutes, then being submerged in water and remaining in it at atmospheric pressure for 15 minutes. 
The strain relaxation slotting method [14] was used to quantify residual stresses. The stresses were assessed on formed laboratory pieces and on industrial tile specimens. In this last case, $150 \times 30 \mathrm{~mm}$ pieces were prepared from the same central zone of the industrial tile by cutting with a diamond disc. Figure 2 displays a schematic representation of the method.

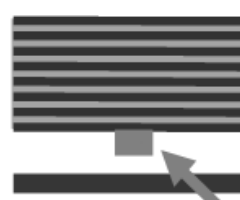

$\mathrm{a}_{1}, \varepsilon_{\mathrm{g} 1}$

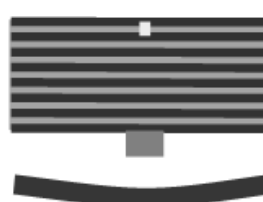

$\mathrm{a}_{2}, \varepsilon_{\mathrm{g} 2}$

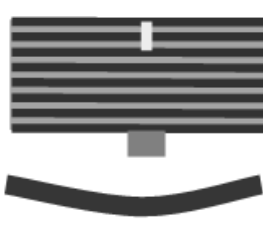

$\mathrm{a}_{3}, \varepsilon_{\mathrm{g} 3}$

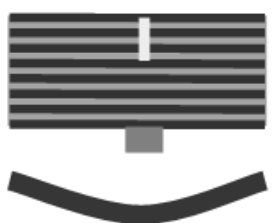

$\mathrm{a}_{4}, \varepsilon_{\mathrm{g} 4}$

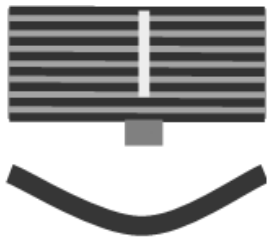

$\mathrm{a}_{\mathrm{n}}, \varepsilon_{\mathrm{gn}}$

strain gauge

Figure 2. Schematic representation of the strain relaxation slotting method applied on a tile specimen

The test consists of gluing a strain gauge on the bottom part of the specimen and then making cuts of increasing depth from the top surface with a diamond disk. The deformation measured with the gauge $\left(\varepsilon_{\mathrm{gi}}\right)$, as a consequence of the bending of the specimen, is a function of notch depth $\left(\mathrm{a}_{\mathrm{i}}\right)$ and relates to residual stress.

In order to calculate the profile of residual stresses, it is necessary to know the relationship between $\varepsilon_{g i}\left(a_{i}\right)$ and the stress in each point of the interior of the piece. Stresses can be expressed as a serial development of Legendre polynomials.

$$
\frac{\sigma_{r}}{E}=-\sum_{k=2}^{n} \lambda_{k} P_{k}(\zeta) \quad \text { Eq. (1) }
$$

where:

$\sigma:$ stress $(\mathrm{Pa})$

E: Young's modulus $(\mathrm{Pa})$

$\lambda_{\mathrm{k}}$ : coefficient of k-degree Legendre's polynomial (dimensionless)

$\mathrm{P}_{\mathrm{k}}$ : k-degree Legendre's polynomial

$\xi$ : dimensionless position coordinate (bottom side $=-1$; top side $=+1$ )

$\lambda_{\mathrm{k}}$ : coefficients are calculated from the measured strain by gauge and the calibration factors $\gamma \mathrm{ij}$ which are theoretically obtained for each geometry by a numerical method (finite elements). The expression that allows to calculate these coefficients is: 
$\left\{\varepsilon_{g}\right\}=[\gamma]\{\lambda\} \quad$ Eq. $(2)$

where:

$\left\{\varepsilon_{\mathrm{g}}\right\}$ : vector of strain values $\varepsilon_{\mathrm{gi}}$

$[\gamma]: \quad$ matrix of calibration factors $\gamma_{\mathrm{ij}}$

$\{\lambda\}$ : vector of coefficients $\lambda_{k}$

The method has been successfully used to determine the residual stress profile inside porcelain tile samples, demonstrating that the residual stresses can be calculated from the resulting $\varepsilon_{\mathrm{g}}\left(\mathrm{a}_{\mathrm{i}}\right)$ curves. The complete development of the equations and procedure to calculate the thermal residual stresses has been described in several previous works [3], [14].

Young's modulus determination was carried out by means of the non-destructive method named impulse excitation technique (GrindoSonic MK5I). The procedure consists of analyzing the transient natural vibration after exciting the test object by means of an external mechanical impulse of elastic nature. More details of the experimental technique and calculation method were previously reported [17]. Three determinations for each sample were performed and the results averaged.

Thermal conductivity of fired specimens was calculated by means of a xenon flash lamp equipment (LFA467 HT Hyperflash, Netzsch-Gerätebau GmbH) which determines the thermal diffusivity from 10x10 mm square specimens cut from the fired bodies. Experiments were programmed from $25^{\circ} \mathrm{C}$ to $1100^{\circ} \mathrm{C}$ at $100{ }^{\circ} \mathrm{C}$ intervals for all tile samples and three measurements per temperature. The thermal conductivity was calculated using Proteus analysis software (Netzsch-Gerätebau $\mathrm{GmbH}$ ) from the measured diffusivity of the pieces, theoretical data (specific heat capacity, $\mathrm{Cp}$ ) and experimental data (dimensions, thickness and bulk density) [18]. In this method, the light beam, which is generated by the xenon lamp, heats the sample lower surface and an infrared detector measures the temperature increase on the sample upper surface. Moreover, to improve the signal of the radiation emitted by the sample, a thin layer of graphite was deposited on both sides of the probe. Argon gas is used to prevent oxidation of the sample at high temperatures. The equation for correlating the thermal diffusivity to the thermal conductivity is:

$\mathrm{k}=\rho \cdot \mathrm{Cp} \cdot \alpha \quad$ Eq. (3) 
where $\mathrm{k}$ is the thermal conductivity $(\mathrm{W} /(\mathrm{m} \cdot \mathrm{K})), \mathrm{Cp}$ is the specific heat capacity $\left(\mathrm{J} \cdot \mathrm{kg}^{-1} \cdot \mathrm{K}^{-1}\right)$ at a certain temperature and constant pressure, $\rho$ is the bulk density of the sample $\left(\mathrm{kg} / \mathrm{m}^{3}\right)$ and $\alpha$ is the thermal diffusivity $\left(\mathrm{m}^{2} / \mathrm{s}\right)$. By using this equation, thermal conductivity at $800{ }^{\circ} \mathrm{C}$ where tempering process occurs was calculated.

\section{Results and discussion}

\subsection{Thermal residual stresses in industrial tiles}

Residual stresses were initially determined on industrial pieces. Two different types of tiles were chosen according to the industrial practice: one tile belonged to a model which dramatically changed its curvature after polishing process, another tile showed no significant curvature change after polishing. In the two cases one tile before and one tile after the polishing process were characterised. Table 2 displays the industrial tiles tested and the reference assigned. A Young's modulus equal to $70 \mathrm{GPa}$ was assumed for calculation.

Table 2. Industrial fired tiles tested for residual stresses

\begin{tabular}{|l|l|c|}
\hline \multicolumn{1}{|c|}{ Fired tile type } & \multicolumn{1}{|c|}{ Industrial process behaviour } & Reference \\
\hline 1 as-fired (unpolished) & Without deformation & $1 \mathrm{U}$ \\
\hline 1 polished & $\begin{array}{l}\text { High convex curvature after polishing } \\
\text { operation }\end{array}$ & $1 \mathrm{P}$ \\
\hline 2 as-fired (unpolished) & Without deformation & $2 \mathrm{U}$ \\
\hline 2 polished & Without deformation & $2 \mathrm{P}$ \\
\hline
\end{tabular}

Figure $3 \mathrm{a}$ to $3 \mathrm{~h}$ shows the results obtained for the pieces detailed in Table 2 . In each case, the first type of graphs (3a, 3c, 3e and $3 g$ ), represents, with punctual values, the evolution of the deformation measured experimentally by the gauge $\left(\varepsilon_{\mathrm{g}}\right)$ as a function of the depth of the cut (a), together with the adjustment performed (solid line), while the second type of graphs shows the residual stress profile calculated from equation 1 along the thickness of the specimen (z) (3b, 3d, 3f and 3h). Acceptably good fits are obtained considering only two terms of the series development of Legendre's polynomials. 


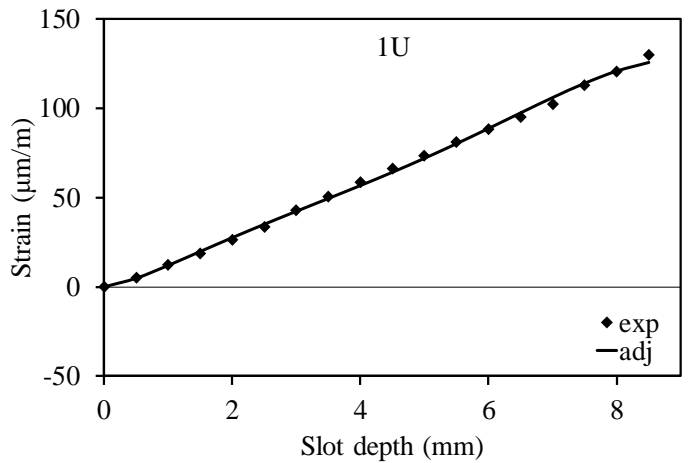

a)

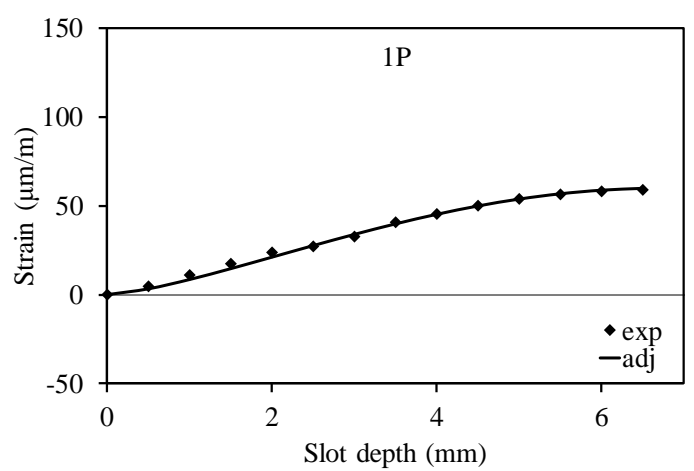

c)

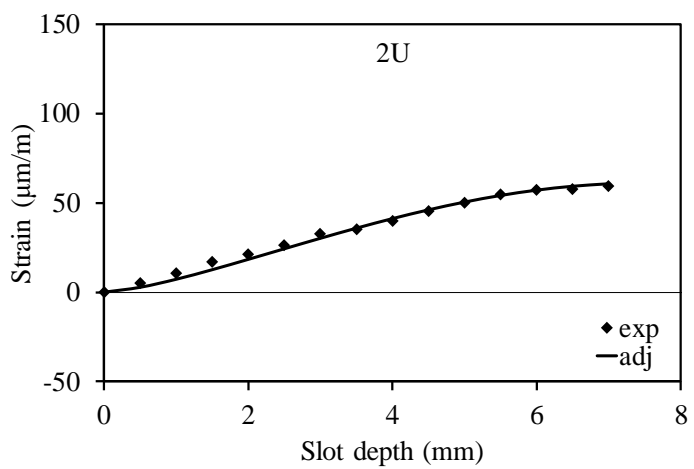

e)

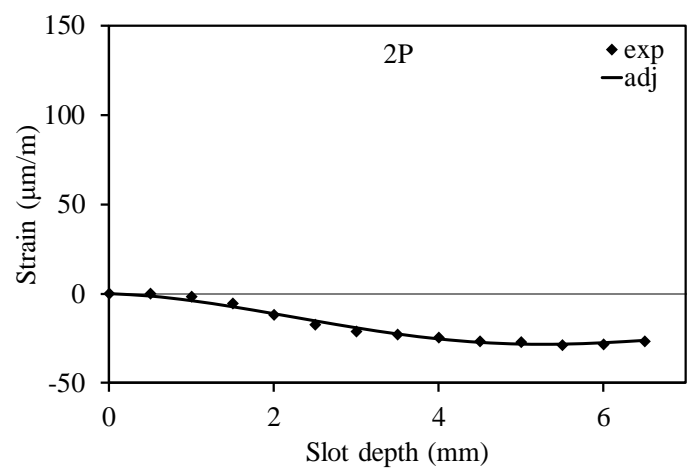

g)

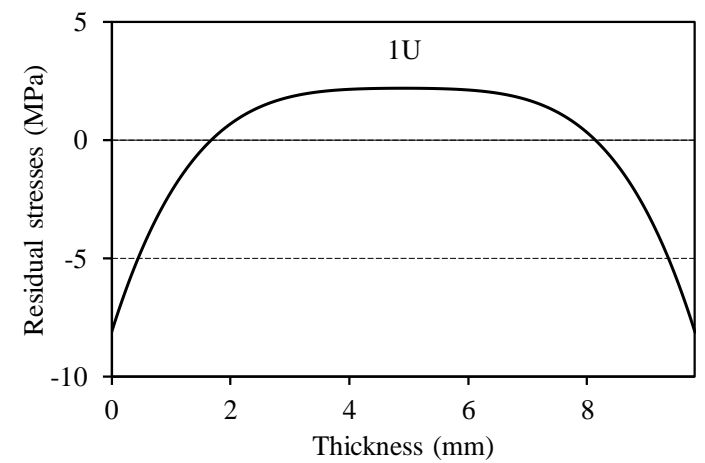

b)

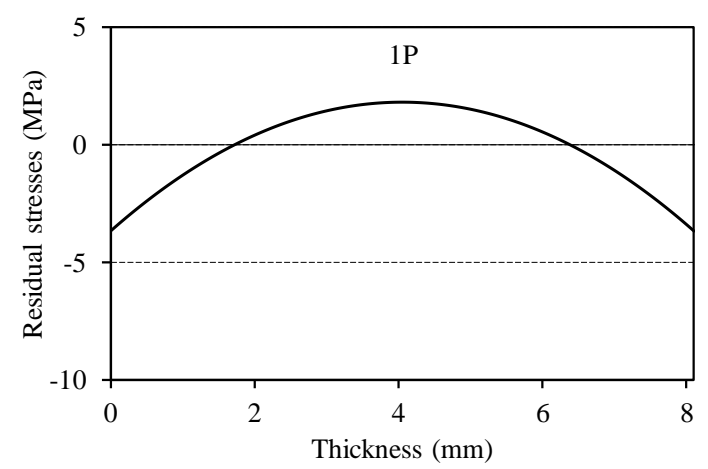

d)

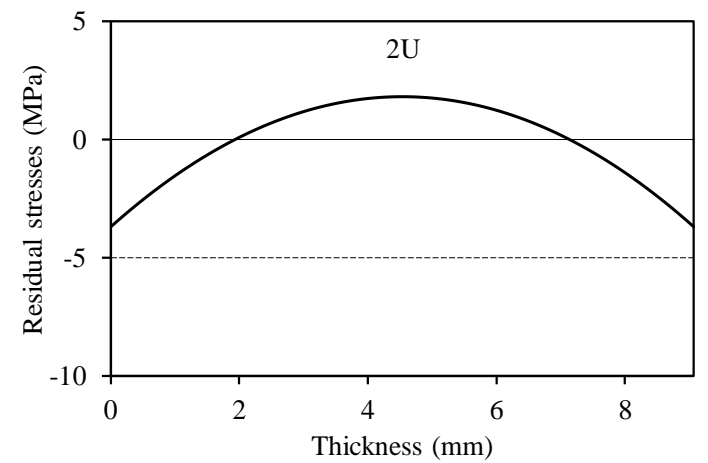

f)

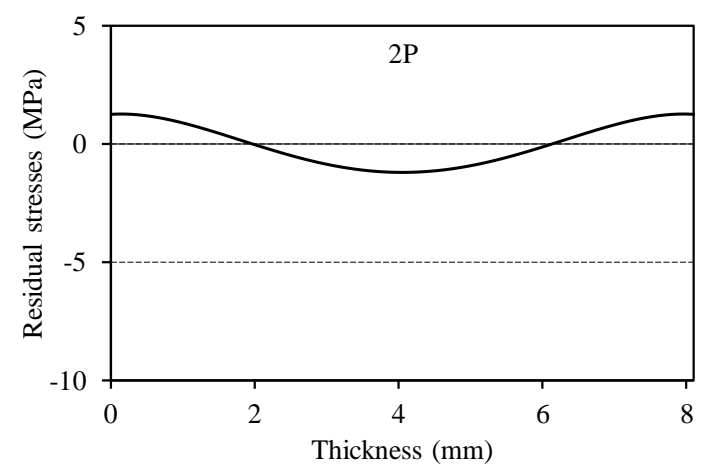

h)

Figure 3. Strain gauge deformation (Figures $a, c$, e and $g$ ) and residual stresses profile (Figures $b, d, f$ and $h$ ) for the four types of pieces displayed in Table 2 
The following results are derived from the observation at the graphs in Figure 3. The surfaces of all the pieces are subject to compression stress (negative values) while the central part appears in tensile stress (positive values). This situation is what can be expected based on the thermal gradients that are established in the pieces during the rapid industrial cooling. These results coincide to a large extent with those observed in previous works [3], [12]. However, Cantavella et al [12] reported some asymmetry in the profiles of residual stresses attributed to cooling differences between the upper and lower faces of tiles during industrial firing. As this asymmetry in the profiles of Figure 3 does not appear, it can be assumed that in this case, the industrial cooling differences were not significant. When comparing the pieces before and after polishing, appreciable differences occur between the two models (type 1 and 2 tiles). On the one hand, although both models display symmetrical stress profiles, the magnitude of the stresses in the fired pieces (before polishing), i.e., samples $1 \mathrm{U}$ and $2 \mathrm{U}$ is very different: around 7.5 MPa of maximum compression stress on the surface of tile $1 \mathrm{U}$ and $3.5 \mathrm{MPa}$ in the case of $2 \mathrm{U}$ sample. When the polishing process takes place, the behaviour of both types of pieces also appreciably differs: model 1 undergoes a significant reduction in the magnitude of the residual stresses (the maximum compression stress on the surface of the piece is reduced from 7.5 MPa to approximately 3.5 MPa), although a clear parabolic profile still persists, however, the model 2 not only drastically reduces the magnitude of the stresses, but the profile becomes practically flat (within the level of precision of the technique). These results corroborate the observations of industrial practice. On the one hand, the piece 1P underwent an important change of curvature after the polishing process, that is to say, as-fired tile $1 \mathrm{U}$ was more or less flat (although strongly stressed) in such a way that after the mechanization produced by the polishing process, the released residual stress resulted in persistent deformation in the tile. In contrast, the type 2 model, after the release of the residual stress accumulated by the piece after firing (much lower than that of sample 1U) a tile, practically without deformation, was obtained as observed in the graph of Figure $3 \mathrm{~g}$.

\subsection{Effect of cooling rate on residual stresses}

Two cooling rates $(\mathrm{C} 1$ and $\mathrm{C} 2)$ were tested on ceramic pieces prepared in the laboratory from industrial powder (STD-T) as set out in section 2.1. The same firing cycle was used at a maximum firing temperature of $1200{ }^{\circ} \mathrm{C}$ (industrial peak temperature) whereas the 
cooling rate was significantly changed. Calculated Young's modulus was $75 \mathrm{GPa}$ for all the pieces, which was determined as described above. Figure 4 shows the residual stresses profiles for the two experiments. As the relationship between the strain and the stress profile curves has already been demonstrated (see Figure 3), only these later curves will be described in subsequent discussions.

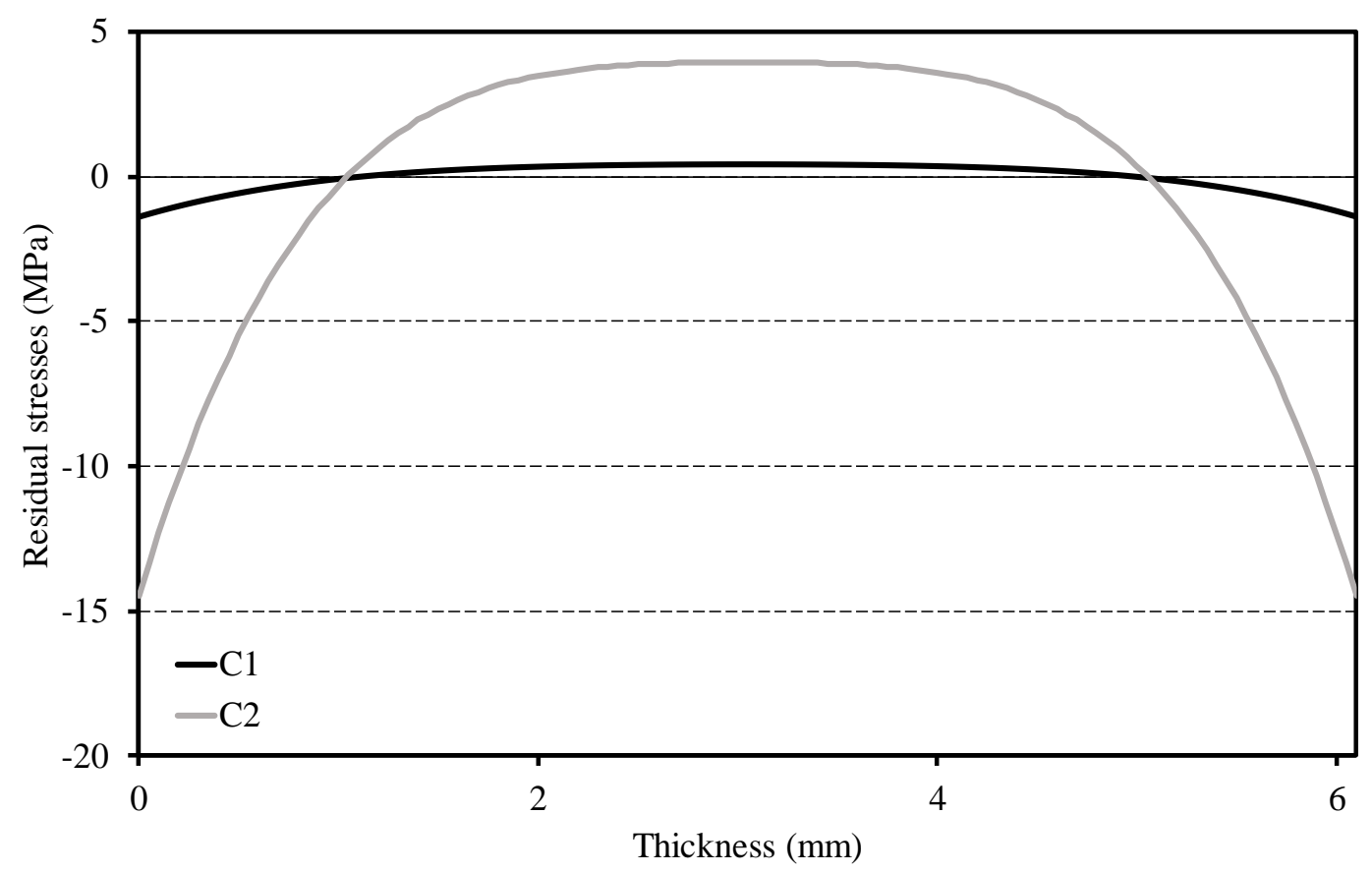

Figure 4. Residual stresses profile for the same piece following two different cooling rates $\left(\mathrm{Cl}\right.$ and C2) (Firing temperature $=1200^{\circ} \mathrm{C}$ )

As observed, cooling rate exerts a dramatic influence on the magnitude of residual stresses. Thus, the maximum compression stress at the tile surface dramatically increases from roughly $1.5 \mathrm{MPa}$ to almost $15 \mathrm{MPa}$ when the cooling rate rises from $\mathrm{C} 1$ to $\mathrm{C} 2$. The influence of cooling rate was already reported by Cantavella et al [19] and De Noni et al [16]. According to these authors, stresses increase as the material cools more rapidly in the temperature range in which the tempering process occurs. In porcelain tile manufacturing, the tempering process takes place in the temperature range in which the glassy matrix developed inside the body is predominantly viscoelastic, i.e. from peak firing temperature $\left(1200{ }^{\circ} \mathrm{C}\right)$ to approximately $650{ }^{\circ} \mathrm{C}$. At this last temperature, tile becomes sufficiently rigid since the glass transition temperatures of natural orthoclase and albite glasses (main glassy phases in porcelain tiles) are $875{ }^{\circ} \mathrm{C}$ and $815^{\circ} \mathrm{C}$ 
respectively [20]. Moreover, the stresses profile keeps symmetric in the two cases as a consequence of the homogeneous cooling process followed by $\mathrm{C} 1$ and $\mathrm{C} 2$ cooling modes in the laboratory.

\subsection{Influence of peak firing temperature on residual stresses}

The effect of peak firing temperature on residual stresses was addressed by using the industrial spray-dry powder STD-T. Three peak firing temperatures were tested: the maximum densification temperature of $1200^{\circ} \mathrm{C}$, one lower (underfiring condition) at $1180{ }^{\circ} \mathrm{C}$ and one higher (overfiring condition) at $1220^{\circ} \mathrm{C}$. In addition, the two extreme cooling rates $(\mathrm{C} 1$ and $\mathrm{C} 2)$ were also carried out.

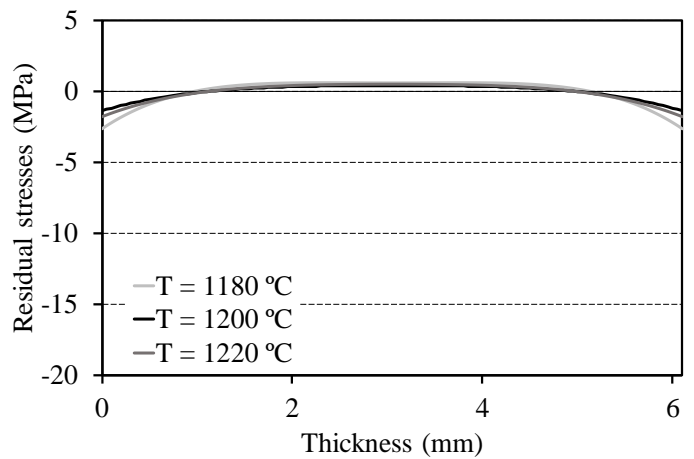

a)

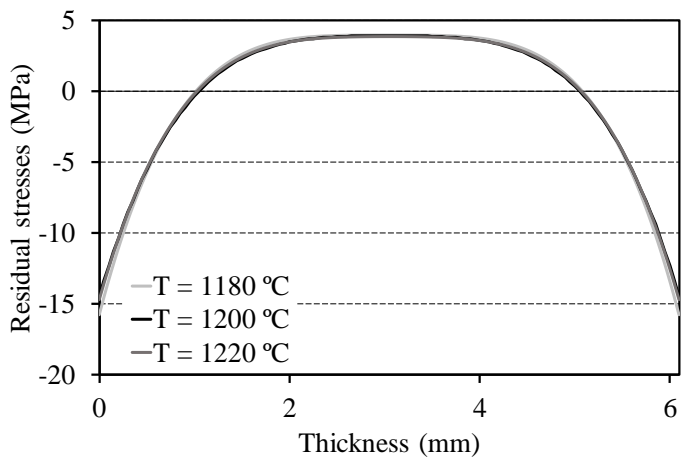

b)

Figure 5. Residual stresses curves for the experiments carried out at three peak firing temperatures, $1180{ }^{\circ} \mathrm{C}, 1200{ }^{\circ} \mathrm{C}$ and $1220{ }^{\circ} \mathrm{C}$ : a) slow cooling rate $(\mathrm{Cl})$ and b) rapid cooling rate $(\mathrm{C} 2)$

Figure 5 plots the residual stresses profile diagram for all the experiments. Firstly, all the curves show symmetric profiles which confirm the homogeneity of the cooling cycles $\mathrm{C} 1$ and $\mathrm{C} 2$ carried out in laboratory conditions. Secondly, the strong effect of the cooling rate is also confirmed, since regardless the peak firing temperature applied, residual stresses provoked by rapid cooling rate $(\mathrm{C} 2)$ are much higher than those produced by the slow cooling mode $(\mathrm{C} 1)$. Finally, for both cooling rates, it can be observed that the peak firing temperature hardly affect the residual stresses curves despite the fact that a quite high temperature variation interval $\left(40^{\circ} \mathrm{C}\right)$ was imposed. 

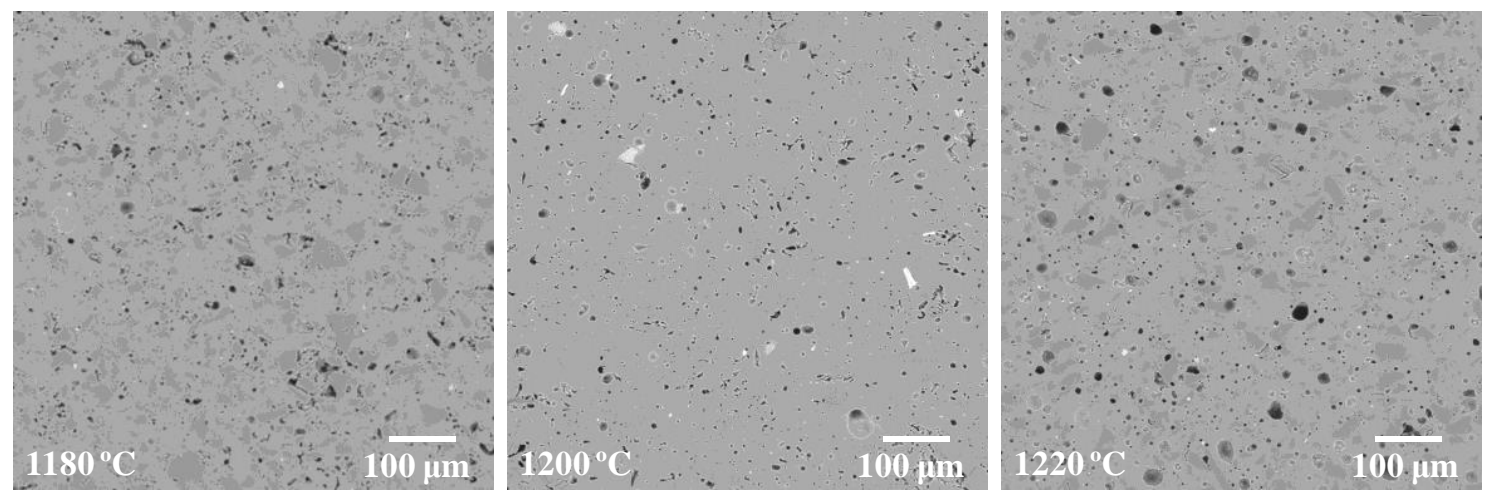

Figure 6. Cross-section SEM micrographs of the samples fired at the three peak firing temperatures $\left(1180^{\circ} \mathrm{C}, 1200^{\circ} \mathrm{C}\right.$ and $\left.1220^{\circ} \mathrm{C}\right)$ following the $\mathrm{C} 2$ cooling mode

Table 3. Bulk density ( $\rho$ ), water absorption (WA), Young's modulus (E) and thermal conductivity $(k)$ values of the samples fired at the three peak firing temperatures following the C2 cooling mode

\begin{tabular}{|c|c|c|c|c|}
\hline $\mathbf{T}\left({ }^{\circ} \mathbf{C}\right)$ & $\boldsymbol{\rho}\left(\mathrm{g} / \mathbf{c m}^{\mathbf{3}}\right)$ & $\mathbf{W A}(\mathbf{w t} \%)$ & $\mathbf{E}(\mathbf{G P a})$ & $\mathbf{k}(\mathbf{W} /(\mathbf{m} \cdot \mathbf{K})$ \\
\hline 1180 & 2.39 & 0.1 & 74 & 3.7 \\
\hline 1200 & 2.40 & 0.0 & 75 & 4.1 \\
\hline 1220 & 2.34 & 0.0 & 72 & 3.9 \\
\hline
\end{tabular}

To better understand the unexpected little influence of the peak firing temperature, samples of the pieces fired at the three peak firing temperatures and cooled with the $\mathrm{C} 2$ mode were examined by SEM. Figure 6 shows the SEM microstructures. Also, Table 3 collects bulk density, water absorption, Young's modulus and thermal conductivity values of the three specimens. As expected, increasing firing temperature from underfiring condition $\left(1180{ }^{\circ} \mathrm{C}\right)$ to the optimum temperature $\left(1200{ }^{\circ} \mathrm{C}\right)$ gives rise to a further reduction of water absorption (porosity) of the fired specimen and consequently a slight increase of bulk density, elastic modulus and thermal conductivity. Additionally, body microstructure becomes more homogeneous comprising less pores with more round morphology as a consequence of the completion of the liquid-phase sintering process [5]. A temperature beyond $1200{ }^{\circ} \mathrm{C}$ results in an overfiring condition characterised by some swelling effect in round pores [21], [22]. Although swelling phenomenon does not influence on open porosity, bulk density decreases and therefore thermal conductivity and particularly Young's modulus are, in some extent, affected by the overfiring condition, 
i.e, the swelling phenomenon provokes the decrease of fired bulk density and consequently of elastic modulus and thermal conductivity. Nevertheless, findings demonstrate that the great variation in firing temperatures which results in the expected changes in body microstructure produced by the advancement of the sintering process does not give rise to sufficient variations in the macroscopic tile properties which can significantly influence the residual stresses profile. This is particularly true if we consider that temperature variation addressed in this research was much larger than that usually produced during the industrial practice. As a consequence, firing temperature should not be used as a regulation variable for residual stresses control in industry.

\subsection{Influence of fluxing behaviour of the body composition on residual} stresses

As set out above, viscous deformations during rapid industrial cooling play a key role for residual stresses appearance in tile manufacturing. For this reason, two typical fluxing additives (dolomite and magnesite) were added to the standard porcelain tile composition (STD-S powder) so as to promote changes in body fluxing behaviour without significantly disturbing the main characteristics of fired specimens. The amounts incorporated to the standard compositions were 2.1 and $0.7 \mathrm{wt} \%$ for dolomite and magnesite, respectively. These amounts were optimised in a previous research [15]. The new compositions were named D (dolomite addition) and M (magnesite addition). Thus, by adding these alkaline-earth providing raw materials, changes in the composition and properties of the glassy phase present inside the firing body are expected to occur. For this same purpose, a highly fluxing composition used in redware floor tile manufacturing was also used (RW powder) [23]. 

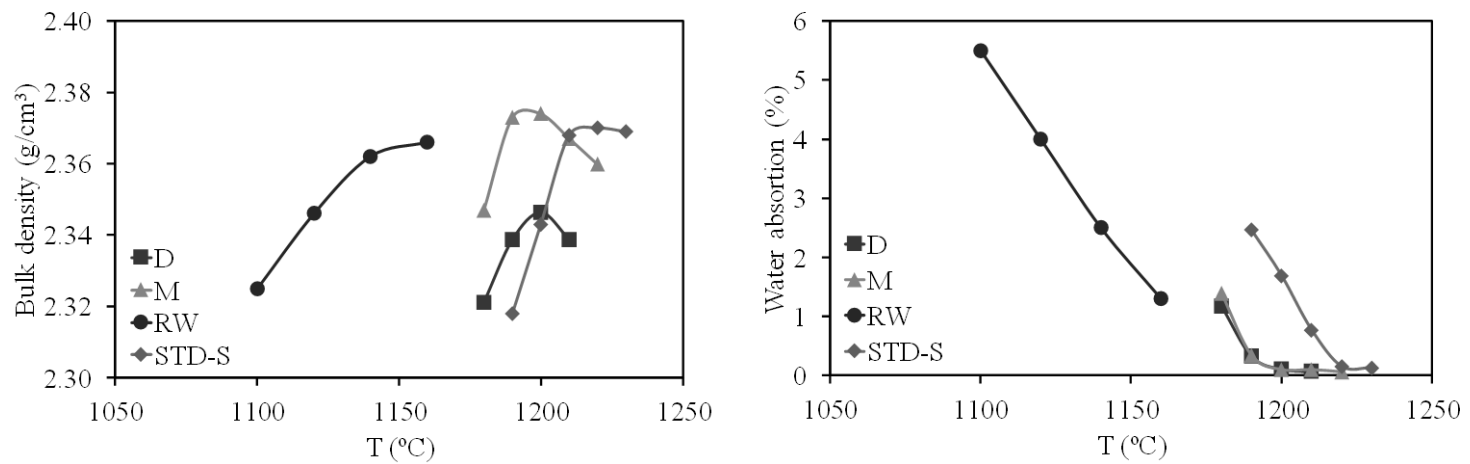

Figure 7. Firing diagrams (variation of fired bulk density and water absorption versus firing temperature) for the three compositions tested: D, $M$ and RW. For comparison, curves of standard (STD-S) powder are also included

The firing diagrams for all these compositions are shown in Figure 7. In this figure, the curve corresponding to the standard powder (STD-S) has been also plotted. On observing these graphs, the role of the fluxing material (alkaline-earth oxides) of the two compounds is evident, i.e. in the two cases the addition of the fluxing material shifts, in more or less extent, the firing curves (fired bulk density and water absorption) to the left (lower firing temperatures). On the other hand, maximum firing density is practically not affected when adding magnesite whereas a clear swelling effect (decreasing of maximum firing density) provoked by dolomite addition was observed. These findings agree with previous research on the fluxing role of alkaline-earth containing raw materials in porcelain tile composition [15]. Concerning the RW powder, firing curves are strongly shifted to much lower temperatures due to the much higher fluxing behaviour of Spanish redware floor tile body which contains significant amount of illitic clayey raw materials [23], [24].

Once analysed the firing behaviour of the three compositions, the following temperatures were chosen for each composition: $1220^{\circ} \mathrm{C}$ for STD-S, $1200^{\circ} \mathrm{C}$ for D and M and $1140^{\circ} \mathrm{C}$ for RW. This temperature selection was based on the market requirements in terms of water absorption for the two types of floor tiles: lower than $0.5 \%$ for porcelain tiles and lower than $3 \%$ for redware floor tiles. Then, fired specimens were prepared at these firing temperatures following the two cooling modes: $\mathrm{C} 1$ and $\mathrm{C} 2$. Young modulus and thermal conductivity were also determined in specimens cooled with $\mathrm{C} 2$ mode. 


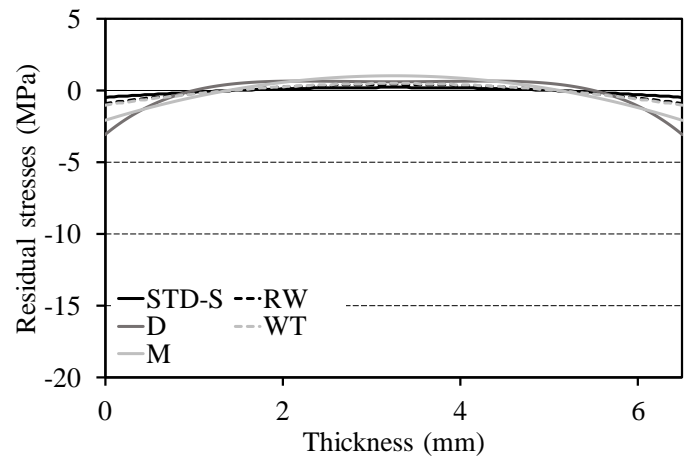

a)

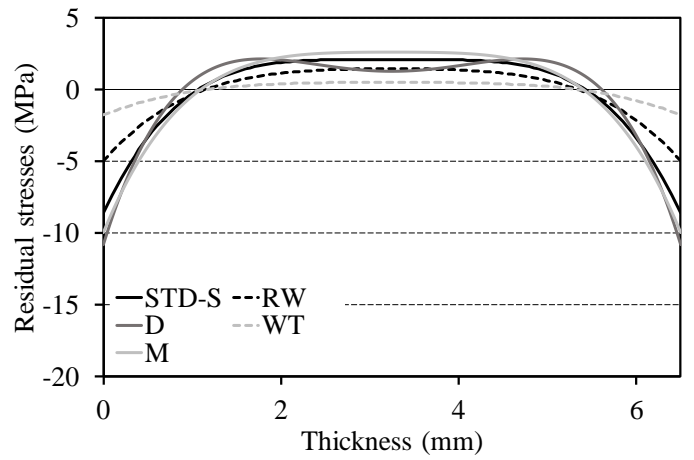

b)

Figure 8. Residual stresses curves for all compositions, STD-S, D, M, RW and WT at the two cooling rates: a) $C 1$ and b) $C 2$

Table 4. Bulk density ( $\rho)$, water absorption (WA), Young's modulus (E) and thermal conductivity $(k)$ values of the samples fired at the corresponding peak firing temperatures (T) following the C2 cooling mode

\begin{tabular}{|c|c|c|c|c|c|}
\hline Composition & $\mathbf{T}\left({ }^{\circ} \mathbf{C}\right)$ & $\mathbf{p}\left(\mathbf{g} / \mathbf{c m}^{3}\right)$ & $\mathbf{W A}(\mathbf{w t} \%)$ & $\mathbf{E}(\mathbf{G P a})$ & $\mathbf{k}(\mathbf{W} /(\mathbf{m} \cdot \mathbf{K})$ \\
\hline STD-S & 1220 & 2.37 & 0.1 & 65 & 3.2 \\
\hline D & 1200 & 2.34 & 0.1 & 65 & 3.2 \\
\hline M & 1200 & 2.36 & 0.1 & 68 & 3.7 \\
\hline RW & 1140 & 2.36 & 2.5 & 48 & 3.7 \\
\hline WT & 1120 & 1.78 & 17.1 & 21 & 2.1 \\
\hline
\end{tabular}

Figure 8 shows the residual stresses curves for the four compositions at the two cooling rates. Table 4 displays the values of bulk density, water absorption, Young's modulus and thermal conductivity of these fired specimens. Overall, same conclusions concerning the effect of the cooling rate as well as on the symmetry of the residual stresses profiles as those inferred in previous sections can be deduced from the observation of these graphs. Thus, these results confirm the good homogeneity and reproducibility of the cooling modes carried out in the laboratory.

Firstly, when compared Figures $5 \mathrm{~b}$ and $8 \mathrm{~b}$ it can be clearly observed that, although stress profiles continue to be very similar (symmetric and parabolic), the magnitude of the maximum compressive stress on the tile surface of STD-T specimens are much higher than that of the STD-S sample (14-15.5 MPa for STD-T samples against $8 \mathrm{MPa}$ for STDS). To understand these differences, we should also compare Table 3 and Table 4 data. 
As observed, Young's modulus of STD-S composition $(65 \mathrm{GPa})$ is much lower than those of STD-T specimens (between 72-75 GPa). Also, thermal conductivity of STD-S sample $(3.2 \mathrm{~W} / \mathrm{m} \cdot \mathrm{K})$ is lower than that of STD-T specimens $(4.1 \mathrm{~W} / \mathrm{m} \cdot \mathrm{K}$ for STD-T sample fired at $1200^{\circ} \mathrm{C}$ ). The reason for these variations is related to the higher densification (higher fired bulk density) achieved from STD-T composition $\left(2.40 \mathrm{~g} / \mathrm{cm}^{3}\right.$ for STD-T specimen fired at $1200{ }^{\circ} \mathrm{C}$ against $2.37 \mathrm{~g} / \mathrm{cm}^{3}$ for STD-S sample). These findings seem to show the effect of Young's modulus of fired specimens on residual stresses appearance whereas the impact of thermal conductivity, at least within the variations observed in the different fired specimens, is not so evident.

With regard to the compositional effect, specimens $\mathrm{D}$ and $\mathrm{M}$ also show similar stresses profile to that of the STD-S sample. Thus, changes in glassy phase composition during sintering process associated to the decrease of peak firing temperature do not result in appreciable variations of macroscopic properties which can exert some influence on residual stresses, i.e. Young modulus and thermal conductivity. Under these circumstances, the predominant role of the fast cooling rate prevails. On the contrary, when a drastic change in composition occurs, i.e. when comparing a porcelain tile composition (STD-S specimen) with a redware floor tile body (RW specimen) variations in macroscopic tile properties take place which impact on residual stresses profile. Hence, as observed in Table 4, Young modulus of RW specimen is $48 \mathrm{GPa}$ which is $30 \%$ lower than that of the STD-S sample, as a consequence of the higher open porosity (higher water absorption) of this type of floor tile. Porosity also exerts a significant influence on thermal conductivity as extensively reported [25], [26]. However, no significant variation of thermal conductivity was found between RW composition and porcelain tile compositions, in fact thermal conductivity of RW specimen was the same as that of $\mathrm{M}$ sample, $3.7 \mathrm{~W} / \mathrm{m} \cdot \mathrm{K}$. Therefore, as the maximum compressive residual stress decreases from roughly $8 \mathrm{MPa}$ to about $5 \mathrm{MPa}$ when moving from the STD-S body to the RW sample the effect of the Young modulus reduction seems to overcome thermal conductivity influence. These findings confirm the observation set out above when compared residual stresses of STD-T specimens with STD-S sample.

To confirm the effect of Young modulus on residual stresses profile, a new specimen of a highly porous tile was studied. Then, a Spanish industrial spray-dry powder for wall tile manufacturing was used to prepare highly porous bodies [23], [24]. Fired specimens were 
prepared at $1120^{\circ} \mathrm{C}$ with the characteristics detailed in Table 4 (referenced WT powder). Residual stresses were also determined for the $\mathrm{C} 2$ rapid cooling. The residual stresses profile is included in Figure $8 \mathrm{~b}$. As observed in Table 4, WT body shows very different properties when compared with floor tile (RW) or porcelain tiles (STD-S, D and M). As reported by literature, highly porous bodies (water absorption higher than 10\%) are required to accomplish with wall tile functionality [23], [24]. As a consequence of this high porosity, wall tiles characterise by much lower Young's modulus and thermal conductivity. Hence, residual stress profile plotted in Figure $8 \mathrm{~b}$ displays a symmetric curve with low stress values on tile surfaces. In fact, the magnitude of the maximum compressive stress is $80 \%$ and $65 \%$ lower than those of STD-S and RW specimens respectively. These findings confirm the contribution of the elastic modulus to the residual stress.

As a consequence of the above, Figure 9 shows an attempt to correlate the magnitude of the maximum residual stress on the tile surface $\left(\sigma_{\text {Rsup }}\right)$ with the value of the Young's modulus of the three different types of studied tiles: porcelain tile (STD-S and STD-T), redware floor tile (RW) and wall tile (WT). The points representing D and M specimens as well as those obtained from STD-T powder at different peak firing temperature $\left(1180^{\circ} \mathrm{C}\right.$ and $\left.1220^{\circ} \mathrm{C}\right)$ are also included. As expected, there is a relationship between elastic modulus and the maximum compression stress developed during the rapid cooling step. As the Young's modulus decreases as a consequence of the increase of tile porosity the body is less prone to accumulate stress due to its higher deformability. The effect of elastic modulus is very clear when comparing tiles with very different characteristics (impervious or porous tiles). On the other hand, the plot evidences the non-linearity of the effect of Young's modulus on residual stresses. Thus, as the tile becomes more and more rigid (higher Young's modulus) the impact of elastic modulus on residual stresses dramatically grows. For this reason, porcelain tiles prepared from different industrial powders (STD-T and STD-S) can lead to tiles with different levels of residual stresses associated to their corresponding Young's modulus values. Nevertheless, for the same type powder, changes in composition (D and $\mathrm{M}$ ) or process variables (peak firing temperature of $1180^{\circ} \mathrm{C}$ and $1220^{\circ} \mathrm{C}$ ) which do not impose significant changes of elastic modulus hardly affect residual stresses. The plot in Figure 9 can then allow to classify the different tile products according to the residual stresses tendency. In this sense, 
composition design acquires great interest in tile manufacturing to develop impervious tile with higher or lower tendency to produce deformations or curvatures associated to residual stresses release.

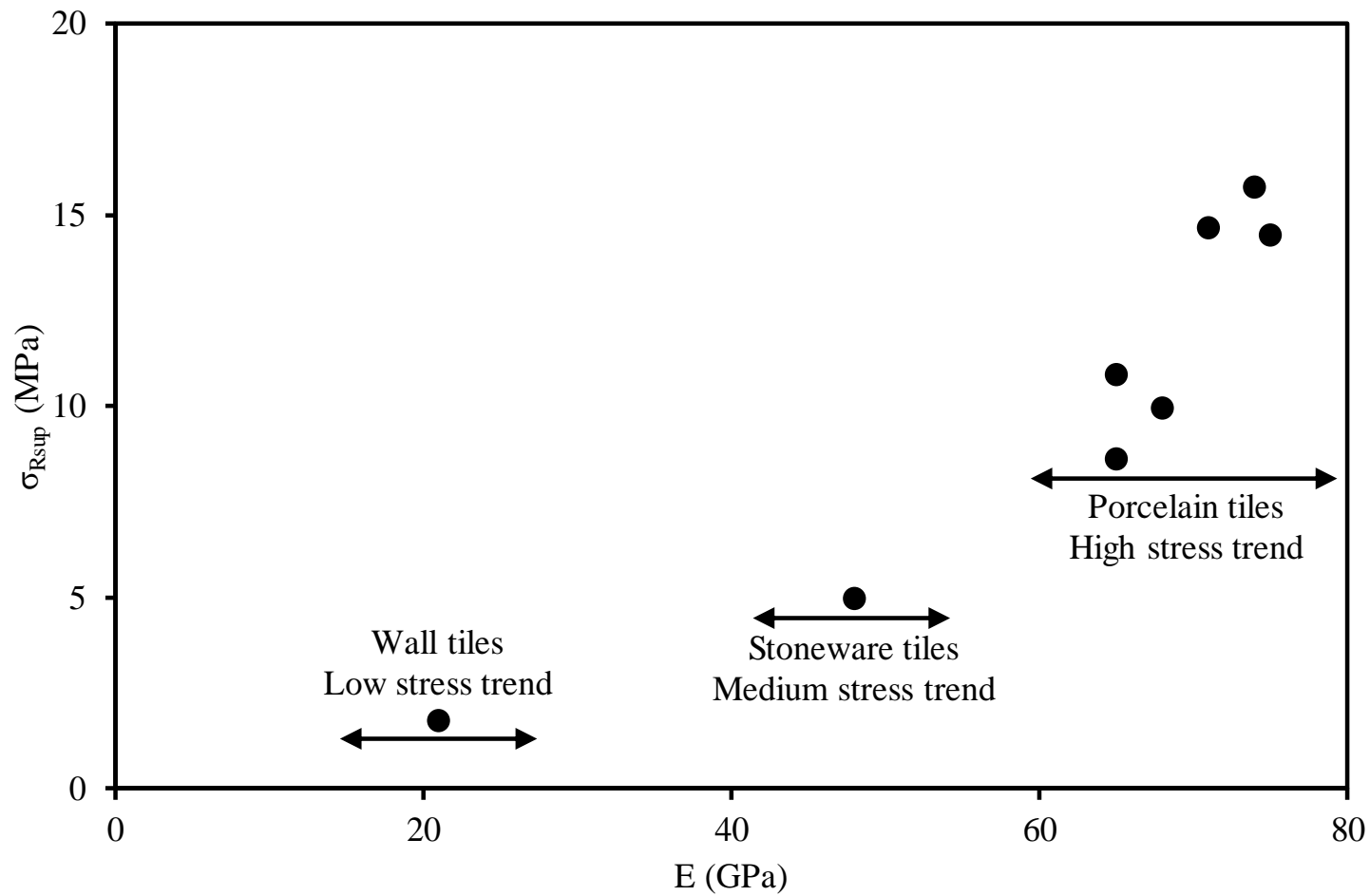

Figure 9. Correlation between residual stress on the surface of tiles $\left(\sigma_{R s u p}\right)$ with Young's modulus (E) for the three different types of tiles: STD (T and S), RW and WT. The points representing $D$ and $M$ specimens as well as those obtained from STD-T powder at different peak firing temperature $\left(1180^{\circ} \mathrm{C}\right.$ and $\left.1220^{\circ} \mathrm{C}\right)$ are also included

\section{Conclusions}

The following conclusions can be inferred from this work:

A rapid cooling step to reproduce industrial process in the laboratory has been successfully implemented. Residual stresses have been determined by using the strain relaxation slotting method adapted to tile specimens.

It has been observed that the surfaces of all the pieces tested (industrial or laboratory prepared) are subject to compression stress while the central part appears in tensile stress as a consequence of the thermal gradients that are established in the pieces during the 
rapid cooling stage. Symmetry of the parabolic residual stress profile denotes homogenous cooling on upper and lower tile surfaces during the cooling step.

Cooling rate is by far the most impacting process variable for the residual stress to occur. In fact, the maximum compression stress at the tile surface strongly increases when the cooling step changes from slow (laboratory) to rapid (industrial) mode. This is because stresses appear as the material cools more rapidly in the temperature range in which the tempering process occurs. On the contrary, little influence of other process variables such as composition fluxing behaviour or peak firing temperature was observed. This is because, when modifying these variables in a reasonable way following the industrial practice, little variation in Young's modulus or thermal conductivity occur which can significantly affect residual stress profile. However, when comparing three types of ceramic tiles exhibiting very different porosity and consequently Young's modulus values, the effect of this mechanical property on the magnitude of the compressive residual stress was demonstrated. Thus, as the tile porosity increases, elastic modulus decreases resulting in lower compressive stresses on the tile surfaces despite the fact that thermal conductivity was also reduced by porosity.

A useful plot to predict residual stresses tendency for different type of tiles was developed. The plot showed the non-linearity of Young's modulus with regard to residual stresses appearance.

Finally, it was also observed that polishing of a stressed tile gives rise to a decreasing of deformation as a consequence of stress release by mechanical grinding.

\section{Acknowledgements}

This research did not receive any specific grant from funding agencies in the public, commercial, or not-for-profit sectors.

\section{References}

[1] V. Cantavella, A. Moreno, A. Mezquita, J.C. Jarque, J. Barberá, A. Palanques, Evolution of Stresses and Curvatures in Porous Bodies during Cooling, Tile Brick Int. (2009) 58-63.

[2] G.W. McLellan, E.B. Shand, Chapter 4 Stress Release and Annealing, in: Glas. Eng. Handb., Third Edit, McGraw-Hill, 1984: p. 4.1-4.17. 
[3] A. De Noni, D. Hotza, V.C. Soler, E.S. Vilches, Influence of macroscopic residual stresses on the mechanical behavior and microstructure of porcelain tile, J. Eur. Ceram. Soc. 28 (2008) 2463-2469. doi:10.1016/j.jeurceramsoc.2008.03.003.

[4] A. Belda, A. Blasco, E. Montiel, M.J. Orts, Glaze Support Adhesion and its Industrial Control, Tile Brick Int. 7 (1991) 15-22.

[5] E. Sánchez, J. García-Ten, V. Sanz, A. Moreno, Porcelain tile: Almost 30 years of steady scientific-technological evolution, Ceram. Int. 36 (2010) 831-845. doi:10.1016/j.ceramint.2009.11.016.

[6] M. Corrado, J.-F. Molinari, Effects of residual stresses on the tensile fatigue behavior of concrete, Cem. Concr. Res. 89 (2016) 206-219. doi:10.1016/j.cemconres.2016.08.014.

[7] X. Huang, J. Sun, C. Zhou, J. Li, Development of Simulation System for Compliance Function and Residual Stress Measurement for Al 2124-T851 Plate, Procedia CIRP. 57 (2016) 591-594. doi:10.1016/j.procir.2016.11.102.

[8] C. Anunmana, K.J. Anusavice, J.J. Mecholsky Jr., Residual stress in glass: Indentation crack and fractography approaches, Dent. Mater. 25 (2009) 14531458. doi:10.1016/j.dental.2009.07.001.

[9] M. Shokrieh, Residual Stresses in Composite Materials, Woodhead Publishing Ltd, 2014.

[10] Z.P. Zhang, S.W. Zhou, Q. Li, W. Li, M. V. Swain, Residual Stresses in Fabrication of Core-Veneered Ceramic Prostheses, Adv. Mater. Res. 97-101 (2010) 2241-2244. doi:10.4028/www.scientific.net/AMR.97-101.2241.

[11] C.B. Tanaka, H. Harisha, M. Baldassarri, M.S. Wolff, H. Tong, J.B.C. Meira, Y. Zhang, Experimental and finite element study of residual thermal stresses in veneered Y-TZP structures, Ceram. Int. 42 (2016) 9214-9221. doi:10.1016/j.ceramint.2016.03.018.

[12] E. Bannier, J. García-Ten, J. Castellano, V. Cantavella, Delayed curvature and residual stresses in porcelain tiles, J. Eur. Ceram. Soc. 33 (2013) 493-501. doi:10.1016/j.jeurceramsoc.2012.09.018.

[13] G.S. Schajer, Relaxation Methods for Measuring Residual Stresses: Techniques and Opportunities, Exp. Mech. 50 (2010) 1117-1127. doi:10.1007/s11340-0109386-7. 
[14] M.B. Prime, Residual Stress Measurement by Successive Extension of a Slot: The Crack Compliance Method, Appl. Mech. Rev. 52 (1999) 75. doi:10.1115/1.3098926.

[15] E. Sánchez, V. Sanz, E. Cañas, J. Sales, K. Kayacı, M.U. Taşkıran, Ü.E. Anıl, Ş. Türk, Revisiting pyroplastic deformation. Application for porcelain stoneware tile bodies, J. Eur. Ceram. Soc. 39 (2019) 601-609. doi:10.1016/j.jeurceramsoc.2018.09.032.

[16] A. De Noni, D. Hotza, V. Cantavella Soler, E. Sánchez Vilches, Influence of composition on mechanical behaviour of porcelain tile. Part III: Effect of the cooling rate of the firing cycle, Mater. Sci. Eng. A. 528 (2011) 3330-3336. doi:10.1016/j.msea.2010.12.086.

[17] A.P.N. de Oliveira, E.S. Vilches, V.C. Soler, F.A.G. Villegas, Relationship between Young's modulus and temperature in porcelain tiles, J. Eur. Ceram. Soc. 32 (2012) 2853-2858. doi:10.1016/j.jeurceramsoc.2011.09.019.

[18] D. Salmon, G. Roebben, A. Lamberty, R. Brandt, Certification of thermal conductivity and thermal diffusivity up to $1025 \mathrm{~K}$ of a glass-ceramic reference material BCR-724, Geel (Belgium), 2007.

[19] V. Cantavella, J. García-Ten, E. Sánchez, E. Bannier, J. Sánchez, C. Soler, J. Sales, Delayed curvatures in porcelain tiles, CFI Ceram. Forum Int. 85 (2008).

[20] M. Dal Bó, V. Cantavella, E. Sánchez, D. Hotza, F.A. Gilabert, Fracture toughness and temperature dependence of Young's modulus of a sintered albite glass, J. Non. Cryst. Solids. 363 (2013) 70-76. doi:10.1016/j.jnoncrysol.2012.12.001.

[21] C. Zanelli, M. Raimondo, G. Guarini, M. Dondi, The vitreous phase of porcelain stoneware: Composition, evolution during sintering and physical properties, J. Non. Cryst. Solids. 357 (2011) 3251-3260. doi:10.1016/j.jnoncrysol.2011.05.020.

[22] E. Sanchez, M.J. Orts, J. Garcia-Ten, V. Cantavella, Porcelain tile composition effect on phase formation and end products, Am. Ceram. Soc. Bull. 80 (2001) 4349.

[23] M. Regueiro, P. Dámaso Padrós, E. Sánchez, Red ceramics in Spain, Ind. Miner. 361 (1997) 61-69.

[24] E. Sánchez, J. García, V. Sanz, E. Ochandio, Raw Material Selection Criteria for the Production of Floor and Wall Tiles, Tile Brick Int. 6 (1990) 15-21. 
[25] T.H. Bauer, A general analytical approach toward the thermal conductivity of porous media, Int. J. Heat Mass Transf. 36 (1993) 4181-4191. doi:10.1016/00179310(93)90080-P.

[26] J.K. Carson, S.J. Lovatt, D.J. Tanner, A.C. Cleland, Thermal conductivity bounds for isotropic, porous materials, Int. J. Heat Mass Transf. 48 (2005) 2150-2158. doi:10.1016/j.ijheatmasstransfer.2004.12.032. 